\title{
ART: TO BE “INSIDE” OR “OUTSIDE” CULTURE
}

\section{THOMAS ORT}

Department of History, Queens College, CUNY

E-mail: thomas.ort@qc.cuny.edu

In the opening pages of his remarkable book about Marcel Duchamp, Jerrold Seigel writes that the French artist "cared more about his personal independence than he did about art itself. Beneath the succession of avant-garde movements there had always lurked an impulse of radical individualism, and no one represented it better than Marcel Duchamp" $(P W, 10)$. Given the subject matter of this essay - the place of art in Seigel's thinking — it may seem odd to say so, but in one respect Seigel's attitude to art mirrors that of Duchamp: he cares less about art itself than about the impulse of radical individualism in modern society revealed through it.

This is not to say that Seigel is indifferent to art or that his attitude to it is identical to that of Duchamp-far from it. But as much admiration as Seigel possesses for the heroism of a figure like Charles Baudelaire, who remained wholly committed to art even as he mined the unstable ground of individual experience on which it stood, he has been preoccupied above all with, let's say, modern art's antiheroes, with those figures who have indulged individualism in its most extreme forms, resisting all limits on their subjectivity, and who in the process have carried art outside the boundaries of art. The chief exemplar of this current is undoubtedly Marcel Duchamp, but Seigel traces its arc from its roots in Bohemia, through figures like Alfred Jarry and Arthur Rimbaud, and finally to its culmination in the avant-garde of the early twentieth century.

This current is by no means exclusive to the sphere of art (and has been examined in its different forms elsewhere by Seigel, notably in The Idea of the Self), but has been powerfully present within it because of what Seigel calls art's "potential orientation toward pure individual autonomy" (MBL, 524). Unmoored from any shared system of values, art in modern society, he argued in Bohemian Paris, has been tasked with the necessity to "create meaning out of the confrontation of an individual consciousness with the world of direct experience" $(B P, 123)$. But this difficult project has been fraught with danger: 
"Because modern art had only the resources of individual personality to invest in the transcendence of everyday life, it had to employ dark energies that had seemed inimical to art before ... [A] rtists had now to construct the ideal out of the very elements of existence that threatened to corrode and dissolve it" (BP, 123-4). The heroism of Baudelaire's life was to shoulder this burden self-consciously, to indulge his private fantasies and derange his senses, in order to map the world's imprint on them and transform the experience into art.

In The Private Worlds of Marcel Duchamp, Seigel approached modern art's individualistic orientation somewhat differently, from the perspective of the changes in urban life that seemed to encourage the liberation of the subjective imagination. Drawing on Robert Herbert's study of French impressionism, ${ }^{1}$ he emphasized the way the mixture of physical closeness and psychological distance characteristic of life in the modern metropolis seemed to make the city "more freely available as a receptacle for the observer's imagination or fantasy" ( $P W$, 45). As a result of its anonymity and objectivity, the city became a kind of canvas onto which individuals could project their moods, states of mind, and private preoccupations. Impressionist painters like Eduard Manet, Claude Monet, or Gustave Caillebotte made this condition a theme of their work, but it was Baudelaire, again, who described it with the greatest precision. Seigel cites a passage from Paris Spleen (1869) in which the poet glimpses an unknown woman through a closed window and then constructs a story of her life that is the pure product of his imagination:

Out of her face, her dress and her gestures, out of practically nothing at all, I have made up this woman's story, or rather legend, and sometimes I tell it to myself and weep ...

Perhaps you will say "Are you sure that your story is the real one?" But what does it matter what reality is outside myself, so long as it has helped me to live, to feel that I am and what I am? (Baudelaire, "Windows," cited in $P W, 45$ ).

Here, the anonymous world of the city nourishes the creative imagination and deepens the poet's sense of his self, but also threatens to cut him off from reality outside the self. Because modern art required that the poet or painter process experience through the screen of individual temperament, it also risked substituting private visions and subjective fantasies for any recognizable reality. As early as the 1870 , the critic Jules Castagnary warned that, for some painters, external reality had become little more than a "pretext for reveries" $(P W, 46)$.

While impressionist painters and poets like Baudelaire may have sometimes indulged their imaginations at the expense of reality, they did not at the same time deny that their private visions were the products of their own

Robert L. Herbert, Impressionism: Art, Leisure and Parisian Society (New Haven and London, 1988). 
subjectivity. Yet Seigel identifies another, even more radical, strand of modernism whose adherents downplayed any role of their selves in the generation of such reveries. "These more radical figures," he writes, "pushed the cultivation of inner experience beneath the level where reality and particular temperament mutually nourished each other, to a point where individuality itself gave way to the impersonality of objective conditions" ( $P W, 48)$. Stéphane Mallarmé, for example, denied that his poetry was born of the externalization of his inner experience, maintaining instead that it was impersonal, that through it he had become a mouthpiece of the universal. Rimbaud similarly proclaimed that his self was not the agent of his own thoughts, that rather than thinking he "was thought," and that the same unspecified external power that did its thinking through him made his poetry "objective" $(P W, 226)$. It is this path that is the chief object of Seigel's attention, the path forged by a form of individuality so radical and so free of the usual limitations that hem it in, that it appears objective and universal.

Seigel's interest in this current is to unravel the claims of vanguard figures like Duchamp to have dissolved their individual subjectivity and subverted their personal coherence, thereby opening themselves up to an unprecedented kind of liberty grounded in chance and fluidity. He boldly argues that far from dismantling subjectivity, such claims are actually a bid to "give the self greater purity and a more exalted claim to independence" $(P W, 13$.$) As such, they are$ part and parcel of the individualistic orientation they wish to transcend rather than a rebellion against it. They represent the aspiration to a form of subjectivity that is lighter, purer, more elemental, and more fluid than the one that takes as its starting point the heterogeneous elements of social and cultural life-the usual building blocks of personal identity. The claim to dissolve the self, therefore, is best understood as an attempt to live "outside of culture," to free the self from the limitations that society and culture impose on individuals $(P W, 13-14)$. This extravagant program, first elaborated by avant-garde artists like Duchamp, has since taken on a multitude of forms, all of which Seigel views with suspicion. Indeed, a significant part of his project has been to show that the attempt to generalize or institutionalize the kind of exalted freedom to which Duchamp and others aspired is a utopian endeavor that can never be realized.

\section{$* * *$}

Seigel embarked on his analysis of these grand programs of individual liberation though an exploration of the institution of Bohemia. In Bohemian Paris, he argued that Bohemia is a space within bourgeois society-not external to itfor the dramatization of ambivalence about its values and social identities. That is, it is a space wherein individuals can enact the tensions and conflicts of bourgeois 
society and demand that they be faced. Perhaps the central conflict dramatized by Bohemians concerned the place of the individual in postrevolutionary society, namely the balance of individual emancipation and social cohesion. The development of each individual's "free subjectivity" threatened all too easily to devolve into selfishness and egotism, corroding social bonds.

While in Seigel's explanation Bohemia is not coextensive with the world of artists, the place of artistic life in modern society nonetheless lies at its core. With the end of the patronage system in the arts and the triumph of market relations, artists lived out the postrevolutionary social transformation. On the one hand, they were now subject to the utilitarian values of the marketplace; on the other hand, they were liberated from dependence on aristocratic patronage and became free to develop their talents in any way they wished, leading to a wealth of aesthetic innovations. Success in the market might therefore be interpreted as the realization of the emancipatory possibilities of the new society. Lack of success, conversely, could be understood as the incapacity to make the most of the new freedoms and thus as a sign of personal failure. In this way, the new society rendered a harsh verdict on those individuals who failed to find room in it for their artistic inclinations. In doing so, it seemed designed to discourage sensitive, poetic natures before they had a chance to blossom and, more broadly, to circumscribe the space available to all people of strong feeling and vigorous imagination, whether they be artists or not.

And yet, one of the earliest commentators on Bohemian life, Félix Pyat, writing in the 1830s, noted a peculiar paradox of postrevolutionary society: even as artists grew apart from the rest of society, increasing numbers of people were claiming to be artists. Pyat understood this expansion of the ranks of artists in terms of a search for originality, a desire for separation from the mores and expectations of existing society. He remarked that these young "artists" were turning themselves into gypsies- "the Bohemians of today" - in their ambition to live more freely and spontaneously, outside the bounds of workaday society $(B P, 17)$. Most of them, he felt certain, would never find success as actual painters or writers, but they persisted in the illusion that they might, and in the meantime neglected their other affairs and responsibilities. Pyat dubbed this malady "artistism" ( $B P$, 18). Although Pyat did not put it in these terms, it seems clear that the rise of artistism is intimately linked to the emancipatory possibilities that individuals experienced in postrevolutionary society. That is, the appeal of the realm of art lay precisely in its provision of a space to explore one's free subjectivity outside the bounds of traditional constraints and responsibilities, and whether or not one had any chance of actually becoming a working artist. "Art" became a place to test the limits and possibilities of one's freedom as an individual.

For Seigel, artistism is part of the prehistory of Bohemia, before Bohemia became fully elaborated in the late 1840 and the 1850 as as the reverse of bourgeois 
life. But the notion already contained one of Bohemia's essential elements: its association not with the creation of artworks but with the life of the artist and its attendant freedoms. Many denizens of Bohemia, to be sure, were true artists, wholly committed to their craft as the materialization of their imagination. But others were drawn to it chiefly as a way of life, as a space wherein they could exercise the full freedom of their senses and imagination without having to translate them into a finished aesthetic form. These were the Bohemians "for whom art meant living the life, not doing the work" $(B P, 58)$. As Henry Murger, author of Scenes of Bohemian Life-the inspiration for Puccini's La Bohème-put it, "Their everyday existence is a work of genius" (cited in $B P, 4,58$ ).

Seigel contrasts this trajectory with that of Charles Baudelaire, who unquestionably inhabited Bohemia but staunchly resisted the confusion of art and life endemic to it. Baudelaire loathed the disorder of Bohemian existence and always emphasized the discipline required to produce genuine works of art. At the same time, Bohemia possessed for him a kind of gravitational allure that he could never escape. Imagining his self as at once centralized and vaporized, concentrated and diffuse, Baudelaire's centralized self corresponded to the contained and controlled dandy in him, while the vaporized self pertained to the dissolute Bohemian. Baudelaire experimented with all manner of self-diffusion, with losing his self in crowds, in sex, in drugs, in nature, in political causes, in whatever really, because it allowed his self to take on the shape and texture of things outside so that he could then reproduce them from within. For him, the Bohemian "cult of multiplied sensation" was a critical part of artistic creativity $(B P, 114-16)$.

But only a part, for the other half of the equation was concentration, without which there could be no real art at all. In his dazzling portrait of the poet, Seigel puts it this way:

The person who first lost himself in the world in order to impress its shape on his spirit had then to condense his being into himself like vapor returning purified from the surrounding air. Then he was ready to give forth a distilled vision that was both nurtured by external reality and born wholly from within $(B P, 117)$.

This distilled vision is art, and it required both Bohemian self-diffusion and dandyish self-containment. In either case, it was wholly dependent on the individual, on the processing of experience through the prism of the self. Whereas intoxication diffused the self, allowing it to receive the world's imprint, the centered individual gave new shape and form to this impress, transforming it by mind and hand into art.

For Seigel, Baudelaire's heroism consisted of his willingness to live for the Bohemian multiplication of sensation while upholding the boundary between art and life that other Bohemians obscured. But many of the poet's modernist successors either were unprepared to shoulder this burden or willfully forsook 
it. One of these was undoubtedly the writer Alfred Jarry, who, in the eyes of André Breton, paved the way for the twentieth-century avant-garde's wholesale annihilation of the distinction between art and life. Seigel ties Jarry's breakdown of this boundary to an aesthetically grounded individualism derived from symbolist poetics and anarchist politics, both of which maintained that no external force had the right to restrain an individual's visions or ideals. On this basis, he argues that Jarry turned his own interiority into confrontation with the world and the limits it imposed on his imagination.

Seigel's analysis of Ubu roi (1896) emphasizes Jarry's partial identification with the play's central character, the bumbling and aggressive Père Ubu, who claws his way to the throne of Poland, only to be deposed soon after he achieves his goal. He draws particular attention to Ubu's aggression and its meaning for Jarry. What they both shared is a dread of the limitations of material existence so intense that the only possible reaction to it was violence. Jarry, like Ubu, was a man who would be king or be nothing, who was "unable to live in a world that did not reflect his own selfhood back to him" $(B P, 316)$. Renowned for his outrageous and provocative behavior-and also for carrying a revolver with him-Jarry wished to abolish the distinction between his thoughts and his actions, his dreams and the world in which he lived. He sought to live by his literary program alone, only to discover that his fantasies were forever circumscribed by the reality of material existence. This made the everyday world practically uninhabitable for him and accounts not only for his exceptional eccentricity, but also for his relentlessly self-destructive behavior. In the end, Jarry drank himself to death and apparently welcomed his demise as the ultimate liberation of his dreams from the materiality of his bodily self. Unlike Baudelaire, who embraced the derangement of his senses through drugs and drink as a byway to art - the only realm of genuine transcendence-Jarry accepted derangement for its own sake, as an escape from the bonds of ordinary existence.

Though Breton hailed Jarry for his breakdown of the boundaries between art and life and considered him one of the surrealist movement's most important predecessors, he always resisted the tendency toward nihilism and personal dissolution that Jarry represented. Breton was likewise drawn to the poetry of Rimbaud, another of surrealism's key guides, but remained wary of his welldocumented descent into systematic sensory disorganization. What he saw in their examples, however, was the attempt to throw off all external constraints on the imagination and to live life according to its claims alone. Indeed, he went further than they in aspiring to transform reality itself from the perspective of dreams and unconscious life, that inexhaustible reservoir of the imagination. With Surrealism, art ceased to be an end in itself and became a vehicle for the remaking of life, a kind of advertisement for a way of life that reached beyond the limitations of the present. "Its purpose," Seigel writes, "was to draw people 
out of the here and now, and into that better life ... [T] he claim to be a poet or an artist was now justified only because it contributed to a life beyond art" ( $B P$, 372). In this way, Breton and the surrealists effaced the boundary between art and life, making art serve ends external to art itself.

And yet, the surrealists were still committed to the production of art, at least most of the time, as a special signpost to transcendence, and, as such, differed from their Dadaist counterparts' more aggressive program of antiart. Despite the groups' shared influences and personalities, Seigel sharply distinguishes between the two, arguing that while the surrealists remained largely committed to the renewal of art, the Dadaists forsook it as a special sphere of activity altogether, indeed reveling in its destruction. To be sure, surrealism's original method of "psychic automatism" possessed much in common with Dadaist practices, namely its grounding of artistic activity in unconscious mental processes unguided by reason, morality, or aesthetic tradition. Seigel maintains, however, that these emanations of unconscious life were not meant to replace art but rather to extend the poetic imagination; they were the starting point of artistic activity, not its terminus. Breton, moreover, remained wary of the flirtation with the irrational inherent to psychic automatism, and so in 1924 steered surrealism toward other, less disorganized repositories of unconscious life. He found these mainly in modern urban existence: in advertising, in shopping arcades, in restaurant menus, in chance encounters, in anything that aroused hidden desire. These were all incitements to an individual's fantasy and therefore potential gateways to transcendence. Through their "explicitly Freudian identification of the psychic depths as the real source of the energy earlier sought in a free life," writes Seigel, the "Surrealists modernized the Bohemian unification of art and life" ( $B P, 383)$.

If this program attained its most characteristic embodiment in works of literature such as Louis Aragon's trance-like Paris Peasant (1926), Seigel also makes clear that the boundaries between surrealism and Dadaism were permeable and unstable. While the surrealists continued to produce more or less recognizable objects of art, they forever justified their activity as aiming "beyond art." They also identified themselves with the spirit of provocation and confrontation more typically associated with Dada and were not immune to mystification and obfuscation, sometimes deliberately driving a wedge between themselves and their audience in order to avoid the false comfort of public approval. And if in practice most surrealists continued to produce recognizable objects of art, they were in principle committed to the devaluation of art. With the arrival of Dadaism and surrealism, the purpose of art was thus fundamentally altered. Now, the vocation of art, Seigel maintains, was "to call men to a freer and more fulfilling existence by releasing the transformative energy present in life itself, and directing that energy against the resistances and barriers that repressed or 
impeded it" $(B P, 384)$. For the avant-garde, art ceased to be associated with the creation of a special category of objects standing apart from the rest of life and became identified instead with a posture of liberation from any limit placed on an individual's imagination.

No artist better embodied this transformation than Marcel Duchamp, who was the first to substitute industrially produced objects for traditional works of art. His readymades called into question the notion of art as a form of creative expression guided by the artist's personality, not to say the existence of the category of art at all. Seigel ends Bohemian Paris with some brief reflections on Duchamp's legacy, anticipating his next major project-a sustained examination of the French artist's career. The Private Worlds of Marcel Duchamp is significant not only for completing a line of inquiry first developed in Bohemian Paris, but also for deepening Seigel's investigation into modern selfhood. In his reading, Duchamp's abandonment of art and proclaimed dissolution of personal subjectivity represent one of the most radical claims for the autonomy of the self heretofore imagined. The form of subjectivity aspired to by him is the model for the purified form of selfhood fully described in The Idea of the Self. The path to Seigel's magnum opus runs through Marcel Duchamp and twentieth-century avant-garde art.

\section{$* * *$}

The brilliance of Seigel's analysis of Duchamp resides chiefly in his ability to discern consistent patterns of meaning in those works of the artist that had long been celebrated for their purposive meaninglessness or free-floating signification. Seigel's distinctive psychobiographical approach enables him to link Duchamp's mysterious and seemingly impenetrable creations to long-term preoccupations partly rooted in his familial and personal relations. In making sense of what others have dismissed as insensible, Seigel exposes as false Duchamp's claims to have dissolved his own subjectivity. Rather than slipping the bonds of his own subjectivity, Duchamp developed a private language that, due to its inscrutability, only seemed driven by accident and chance, whereas it was in fact a vehicle for the persistent exploration of his inner concerns and for the maintenance of the purity of his self.

One key to these preoccupations, according to Seigel, is a note first written by Duchamp in 1913 and subsequently published by him in 1966 in reference to his work the Large Glass (formally known as The Bride Stripped Bare by Her Bachelors, Even, Fig. 1), his most complex and arguably most important creation. The note describes - in rather cryptic terms - the experience of gazing into shop windows, of having one's desire aroused by the displayed objects, and of the inevitable disappointment that accompanies their possession. The note suggests that a state of perpetually aroused desire had for Duchamp far more 


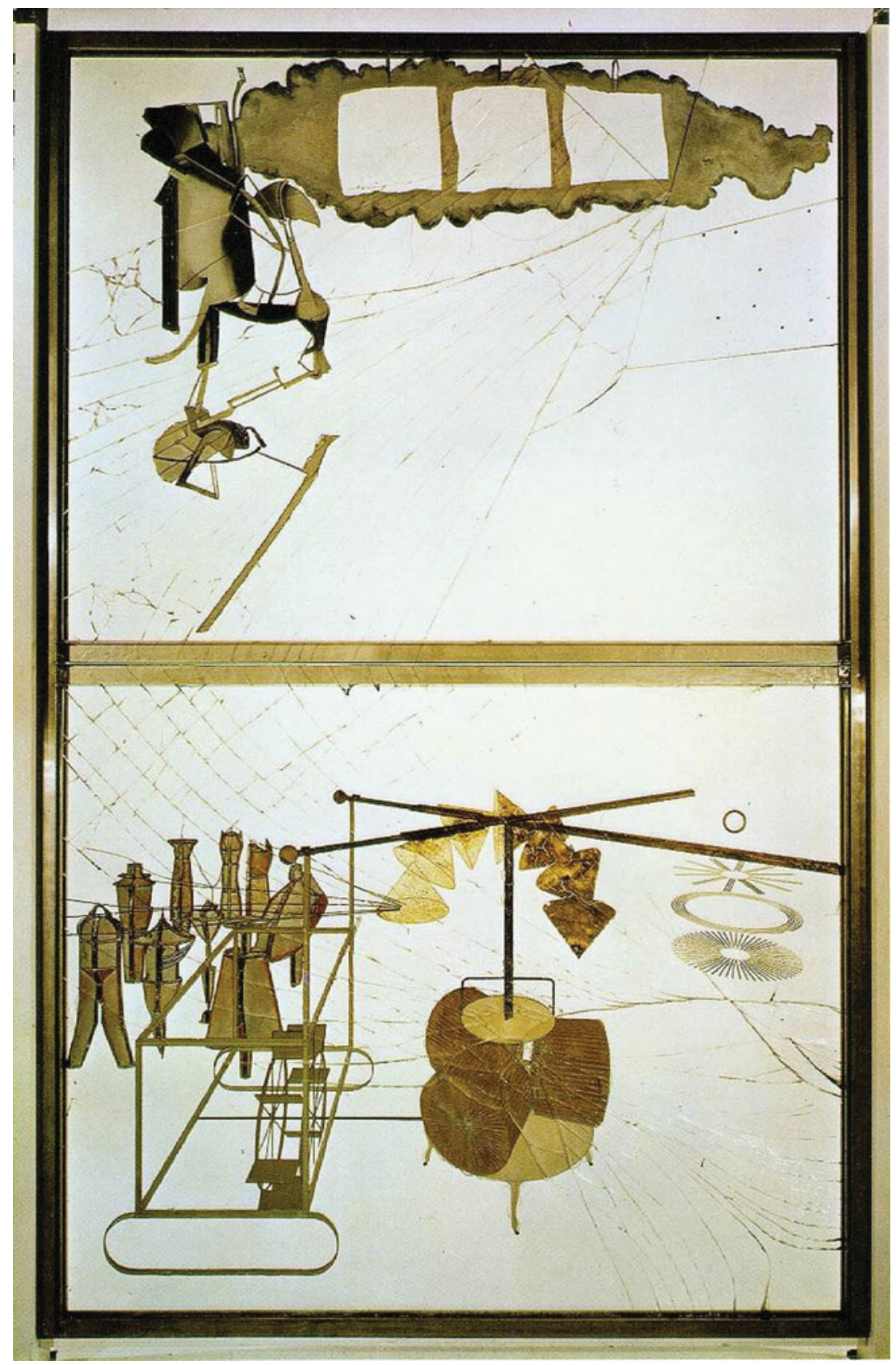

Fig. 1. (Colour online) Marcel Duchamp, The Bride Stripped Bare by Her Bachelors, Even (1915-23). (C) Succession Marcel Duchamp/ADAGP, Paris/Artists Rights Society (ARS), New York, 2017. 
appeal than the satisfaction thereof because, as Seigel states, "desiring carries us outward toward a still-imagined state, promising an expanded and altered form of existence; but once satisfaction occurs, we have only the particular things chosen, and we return, frustrated and chagrined, to the previous boundaries of the self." Or, to put it another way, Duchamp preferred his transactions with the external world to be governed primarily by (unfulfilled) desire because it allowed "the self to set the terms of its relations with objects" $(P W, 30-31)$. In such a state, the self is not required to make any compromises with external reality; it resides in a hermetic realm of pure aspiration. Once desire is fulfilled, however, the seal is ruptured and the self is subject to the social and material limitations of that which is possessed. What Duchamp was seeking, in Seigel's view, was a kind of selfhood "freed of the particular opinions and practices of a given culture, and able — at least in the imagination — to transcend the limits that any and every culture imposes on its members" $(P W, 13)$. This is the meaning of Seigel's assertion that Duchamp and other avant-garde artists aspired to live "outside of culture."2

The contrast between Duchamp's work and that of his cubist contemporaries also helps clarify his inclinations. Although Duchamp was a sometime member of the Puteaux cubist circle along with his brothers Gaston and Raymond, he was never comfortable in a group setting and definitively parted ways with it in 1912 when its leading personalities, Albert Gleizes and Jean Metzinger, rejected Nude Descending a Staircase - the painting that made him famous in America-for an exhibition they were organizing. In their well-known pamphlet On Cubism, Gleizes and Metzinger described the act of contemplating a cubist painting as effecting "a sensitive passage between two subjective spaces," that between viewer and artist. They acknowledged cubism to be an art of subjectivity, but insisted that those working in the new style endeavored to enclose their subjective experiences "in a symbol likely to affect others." That is, they emphasized the importance of communication between subjective spaces, the necessity for crafting symbols that would enable a passage between the two. They harshly condemned as obscurantist art that failed to effect such a transition, that reveled in its unintelligibility or deliberately attempted to "fabricate puzzles" (cited in $P W, 52$ ). Although it is impossible to know if Gleizes and Metzinger had Duchamp in mind when they penned this critique or when they rejected his painting for their show, Seigel clearly believes that this may have been the case, for Duchamp was already pushing

In his most recent book, Between Cultures, Seigel further explores the resistance to the limits that all cultures impose on individuals. Here, however, his interest is on self-conscious attempts to straddle two cultural situations, to inhabit a space "between cultures"- to be at once part of and distanced from both cultures - rather than to live, more extravagantly, "outside of culture," in a state of pure individual autonomy. 
aesthetic subjectivity to its limits, even in his early works. He was renouncing the passage between subjectivities for the freedom of his own private world.

Whatever notoriety Nude Descending a Staircase brought him in 1915, Duchamp became best known for his readymades: ordinary or slightly altered objects elevated to the status of art. The readymades, in Seigel's words, "stand as Duchamp's signatory challenge to artistic tradition, his irreparable violation of the sacred precinct where art had reposed in sovereign independence from the rest of life" $(P W, 115)$. They once and for all abolished the line between art and nonart, showing that any object that could be experienced aesthetically could be understood as art. As art historian Clement Greenberg explained, through the readymades Duchamp effectively redefined the meaning of art as "an act of mental distancing - an act that can be performed even without the help of sense perception. Any and everything can be subjected to such distancing, and thereby converted into something that takes effect as art" (cited in $P W, 116$ ).

As insightful as such readings are, Seigel suggests that Duchamp came to the readymades for other reasons as well: he saw them as a "defense against personal fixity," as a way of avoiding repetition and becoming linked to any particular style, taste, or habit that might stabilize his personal identity. Crucially important to his designation of objects as readymades was that they be chosen out of "visual indifference"; that is, more or less randomly, without advance planning and without regard for the nature of the object. The idea behind such indifference was not merely to demonstrate that any object could be appreciated as art, but rather to forestall the possibility that any trace of the artist's personality would enter into the process of selection. As such, readymades were "a way to preserve an undefined, fluid existence, in contrast to that of the conventional artist, whose presence in a series of works could be recognized by known elements of style" $(P W, 116)$. They were thus conceived not only as a means of challenging the traditional boundaries of art, but also as a vehicle for the dissolution of artistic subjectivity.

But in this aspiration at least, they failed, for, as Seigel strikingly reveals, the readymades were by no means selected out of indifference. On the contrary, they are marked by Duchamp's long-standing preoccupations and form part of the private symbolic language he was developing through his other works, especially the Large Glass. For one thing, Duchamp did not articulate the concept of the readymade until 1915, two years after he had begun working with found objects. His well-known Bicycle Wheel (an inverted wheel of a bicycle mounted on a stool, Fig. 2) dates to 1913, while Bottle Rack (a bottle-drying rack) dates to 1914. These readymades avant la lettre were not originally conceived as the substitutions for art of which they would later become representative, but rather are best understood, according to Seigel, as akin to Duchamp's many puns and thus as fully laden with significant though largely private meanings for the artist. 


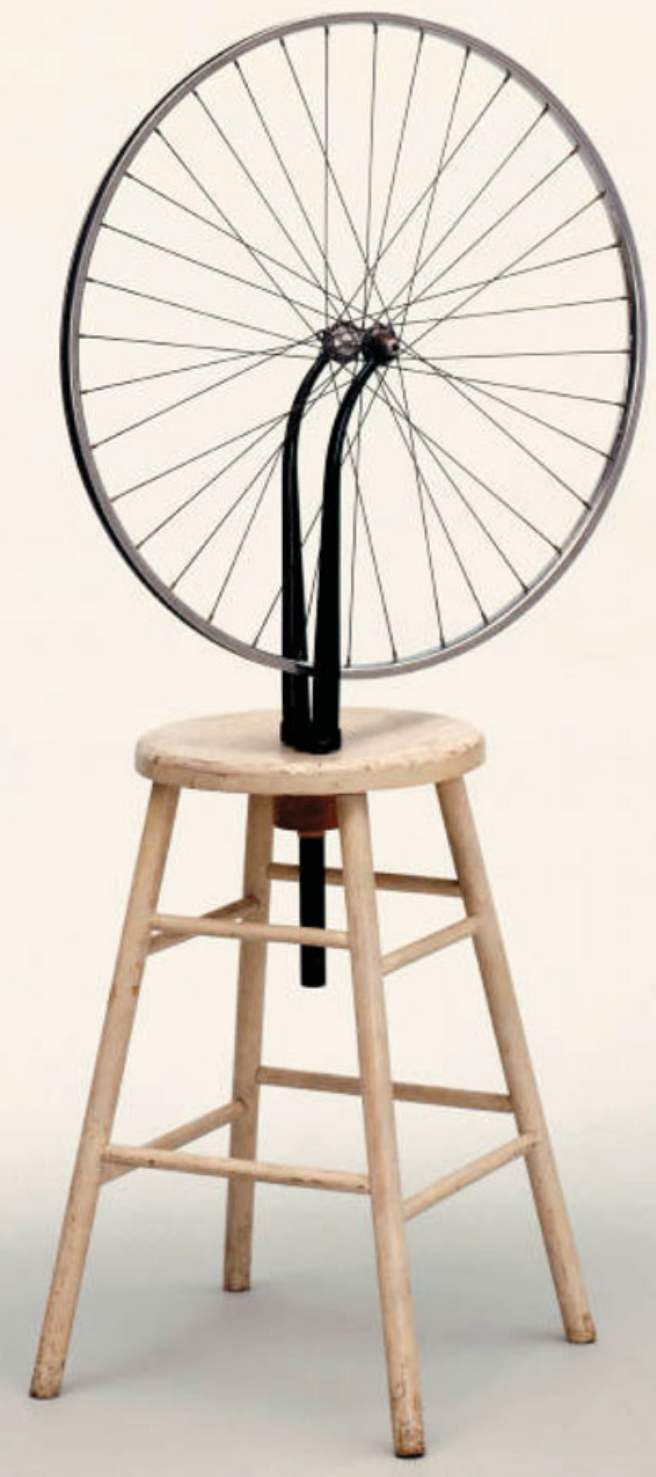

Fig. 2. (Colour online) Marcel Duchamp, Bicycle Wheel (1951, reconstruction of lost 1913 original). (C) Succession Marcel Duchamp/ADAGP, Paris/Artists Rights Society (ARS), New York, 2017. 
Bicycle Wheel, for example, was created at a time when Duchamp was engrossed with the idea of motion and seeking to transcend linear movement in favor of the kinds of movement that produced no directional progress, or what he called "delay," a central feature of the Large Glass. Bicycle Wheel likewise visually echoes elements of the Large Glass, namely its waterwheel and chocolate grinder, both notable for their nonlinear, rotational movement and thus also symbolic of "delay." Bottle Rack is similarly marked by Duchamp's preoccupations. The phallic implications of the rack's prongs - extended upward, awaiting wet bottles to be fitted onto them - are difficult to overlook, and Duchamp, apparently, did not deny such a reading, belying his claim to have selected the object out of indifference. But Seigel suggests an even more pointed interpretation of Bottle Rack, linking it directly to the themes of the Large Glass: "What makes the rack resonate so perfectly with the Large Glass is the absence of the bottles for which the prongs call out ... so that the female counterpart to the symbolic male anatomy exists only by being imagined; male and female await each other in fantasy, while being deniedor spared-physical contact" $(P W, 126)$. These proto-readymades, then, were by no means the product of a dissolved subjectivity; on the contrary, they form part of a private language designed to express Duchamp's persistent concerns.

Even Duchamp's most notorious readymade, Fountain (Fig. 3), the porcelain urinal he submitted to an exhibition in New York in 1917, well after he had articulated the concept of the readymade, is not free of the artist's personality. For one thing, it was clearly intended to provoke and offend and, as such, was hardly selected out of indifference. More importantly, it too contains the marks of Duchamp's preoccupations and can be readily linked to the Large Glass. The one way Duchamp altered the urinal was by displaying it on its side, inviting viewers to contemplate it from the perspective of the hole-the orifice-normally used to pipe water into the curvilinear, almost uterine, space of the urinal. (And what else is a urinal besides a receptacle designed to capture the bodily fluid of a man?) As such, Fountain "called up the imaginary relations between male and female personae that existed in his conception of the Large Glass" $(P W, 137)$. It functions too as a sort of female counterpart of the bottle rack. In this case, it is a female presence that beckons for a male complement that never arrives, again echoing the suspended desire or "delay" of the Large Glass. In Seigel's analysis of the readymades (and many of Duchamp's other works), the French artist's brilliance seems to reside less in the successful effacement of his personality than in the consistency and thoroughness with which he explored his private concerns and constructed a symbolic language to express them.

And yet, it is important to reckon with Duchamp's claims to have slipped the bonds of his subjectivity because, in doing so, he believed he had attained a special kind of liberty characterized by fluidity and instability, and free from the usual constraints of culture. Seigel concludes Private Worlds with a discussion 


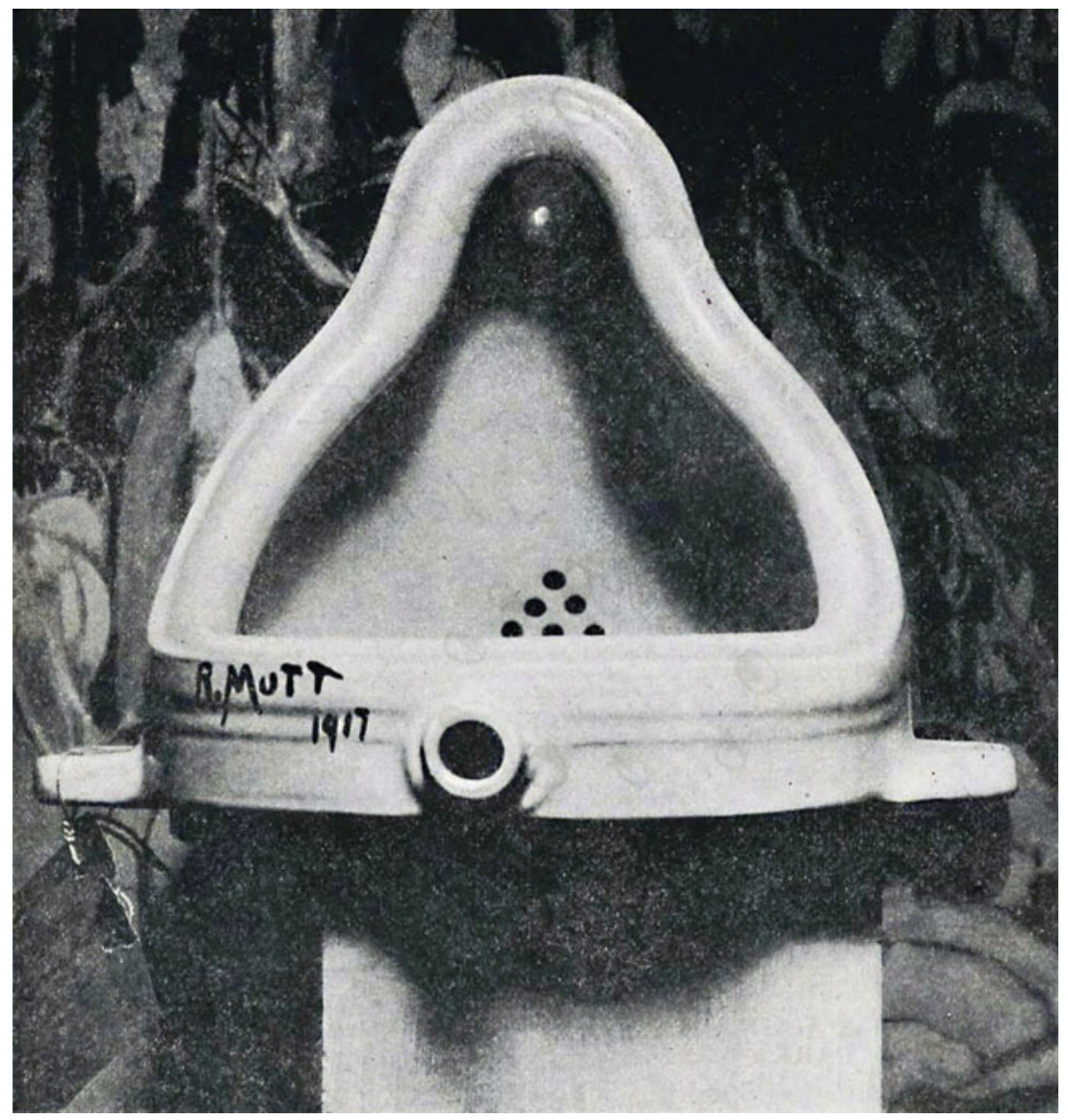

Fig. 3. (Colour online) Marcel Duchamp, Fountain (1917, original, photographed by Alfred Stieglitz). (C) Succession Marcel Duchamp/ADAGP, Paris/Artists Rights Society (ARS), New York, 2017.

of the nature of the freedom aspired to by Duchamp, contrasting it to other liberatory projects pursued by modernist and avant-garde artists in the nineteenth and twentieth centuries. In the process, he lays out his understanding of the differing kinds of freedom the sphere of art offers in modern society. As such, this discussion serves as a useful coda to this essay.

$* * *$

While Duchamp never became a fully fledged member of the French surrealist movement, André Breton admired him greatly because he saw in him an artist who found his way around one of the central dilemmas of avant-garde artistic 
practice. If the shared aim of vanguard movements was to reinvigorate life from a basis in art, infusing it with the freedom of the imagination previously confined to the sphere of art, then they seemed to forever miss their mark. The necessity to articulate their goals through a new artistic style or program meant that each venture had a tendency to become a matter of habit and routine, soon arresting the imagination in a prescribed form that had at first lent it wings. It was this tendency toward fixity and the ossification of the imagination that Duchamp had eschewed through his readymades. Seemingly lacking any consistent stylistic features and apparently selected at random, they embodied the freedom from every fixed condition of life that Breton exalted.

Seigel contrasts this form of freedom to that which the poet Paul Éluard located in Picasso's art. Eluard saw in Picasso an artist who traveled the difficult "path from subject to object," who found a means of translating his intensely subjective inner experiences into external forms that were nonetheless accessible to others. The symbolic language he constructed possessed a "poetic reason" that enabled communication across subjectivities rather than closing it off $(P W, 236-7)$. Seigel maintains that what Eluard appreciated in Picasso was his articulation of a style, "a visual synthesis of a subjectivity with the objects that confront it" ( $P W, 237)$. A style in this sense opened people up to new dimensions of experience by allowing them to participate in an artist's highly personal encounter with the world without losing their way. In short, Picasso invented a style that expanded rather than contracted shared forms of experience and enabled rather than foreclosed what Gleizes and Metzinger called "a sensitive passage between two subjective spaces" (quoted in $P W, 52$ ).

It was this transitional space that Duchamp renounced in the Large Glass and the readymades. Duchamp found freedom precisely in the dismantling of common ground between artist and audience because it ensured the preservation, for him at least, of a private space uncontaminated by exchange with the external world. According to Seigel, the disparity in the kinds of freedom represented by the examples of Duchamp and Picasso arise from the differing ways they conceive of the relationship between the self and the world. The clarity and force of his explanation deserves quotation at length:

Duchamp's pure freedom requires that the inner play of fantasy meet the world of material things wholly on the former's terms: it is lost when one breaks the shop window and discovers that the objects which beckon there only yield to possession by imposing the actuality of their limitations on desire's infinite wish. Such freedom cannot be experienced through direct interaction with the world, but only at a remove ... Such spaces are worlds in themselves, into which objects enter only as symbols, so that the ideas they stand for encounter no material, mundane resistances, but echo endlessly off each other in a kind of constant interior reverberation. $(P W, 239)$ 
The kind of freedom embodied by Picasso's art, on the other hand,

is less pure but also less isolated, is fulfilled not in self-reference but in representation, the power to see the world in some independent way. Being able to give the world a personal shape does not liberate anyone from the conditions of living in it but testifies to an individual's ability to discover possible ways to think and act that had not been visible before; each style sets up a particular mode of interaction with the external world, giving to it an order it does not possess in itself. $(P W, 240)$

This latter form of freedom may be modest as compared to Duchamp's, but its emancipatory potential lies in its recognition that every individual may also be, or perhaps already is, the author of another such personal world. In this vision, the self finds its freedom in ongoing exchange with the external world, in the ceaseless invention of new representations of this interaction-new styles. No one representation is true or universal; all are partial and particular, the product of one subjectivity's relations with the world. Art constituted in this way belongs "to the self that forms its being within the world" $(P W, 242)$. The readymades do not. They are animated by a type of selfhood free of the usual limitations that society and culture impose on individuals; they are unalloyed receptacles of the imagination, ready to embody any private symbolic intention projected onto them. It may seem paradoxical that industrial products are more open to such intentions than traditional objects of art but, as Seigel explains, it is precisely their anonymity and impersonality that make them so available to individual fantasy.

It should be clear, then, that one way of thinking about art locates its freedom within the heterogeneous elements of social and cultural life, and seeks to craft ever new resolutions to its multifarious demands. The other kind-Duchamp'sfinds it outside: it casts off "the burden of reconciling contradictions that membership in complex cultures imposes on individuals, opening the way to a lighter, more elemental kind of selfhood" $(P W, 13)$. The abolition of the boundary between art and life is nothing less than the abolition of the distinction between the self and the world, between the realm of the imagination and the world of material and cultural limitations. The attempt to live life as if it were a work of art is an attempt to live by way of imagination alone, undiluted and unadulterated by the constraints of society and culture. Under the guise of a dissolved subjectivity, it represents the most radical form of individualism that modern culture has spawned: a form of selfhood purified of any contamination by the external world.

And it is precisely in this aspiration that the central irony of the avant-garde project inheres. Conceived in rebellion against bourgeois society, it actually represents the most complete unfolding of its core individualistic principles: Duchamp and his predecessors and heirs pushed art's "potential orientation toward pure individual autonomy" to its limits $(M B L, 524)$. In other words, for all of its sound and fury, the revolt of the avant-garde was a revolt from 
within the culture of bourgeois modernity, not external to it. Or, as Seigel puts it, "Increasingly we understand that the avant-garde belongs to our culture, the culture of modernity, and never more wholly and loyally than in its claims to be in revolt against it" $(P W, 15)$. In short, it is not possible to be "outside of culture." The dreams of absolute rebellion and the freedom of a dissolved subjectivity were born squarely within modern culture, not outside it.

Paradoxically, as much as Duchamp has become the standard-bearer for the avant-garde abolition of the boundary between art and life, he may have understood the limits of this project better than most because for him the endeavor was always a private one. Unlike so many of his disciples and admirers, he did not believe that the freedom sought therein could be generalized or institutionalized, that it could be realized through a project of political transformation. Scrupulously keeping himself at arm's length from the revolutionary political projects of his day, Duchamp aspired to a kind of freedom that belonged to the "realm of pure inwardness" and could not be extended to the public or material world $(P W, 248)$. Indeed, he may have pointed to this distinction in his confounding and much-reviled final work, Given (Fig. 4).

Inviting viewers to peer through a peephole in a heavy wooden door, Given reveals a totally nude woman, legs spread in possible postcoital satisfaction. For Seigel, this crude, almost pornographic, work was Duchamp's way of completing his "definitively unfinished" Large Glass, of transporting the bride and her bachelors from the arena of expectation and unfulfilled desire to that of possession and fulfilled desire- to the world of ordinary material existence. Duchamp left instructions that Given not be displayed until after his death, as if to say, in Seigel's words, "When the breath of desire no longer lifts me into the world of unrealized aspirations, then the elements of my picture will return to the dead world of time and space, where we can examine them as they would be in a state that belongs wholly to the here and now" $(P W, 110)$. Given is the condition in which nothing is left to the imagination and in which there is no transcendence: everything is given, materialized, satiated, and, ultimately, dead. It is "an account of what art becomes when erotic energies, preserved as engines of fantasy within the delay of the Large Glass, turn from imagination to ordinary life" $(P W, 111)$. And it was precisely what Duchamp believed art should never be (and why so many of his admirers were perplexed and repulsed by it).

This may be why, perhaps, he resisted the impulse of his peers to realize in politics the freedom he sought through art. To do so would be to materialize that which belongs to the realm of imagination and desire, to break the glass of the shop window and submit to the limitations of material possession, a transaction that can only issue in disappointment and disillusion—or worse. In respecting the boundary between private fantasy and shared reality, Duchamp also preserved something of the boundary between art and life. Art for him remained a sphere 


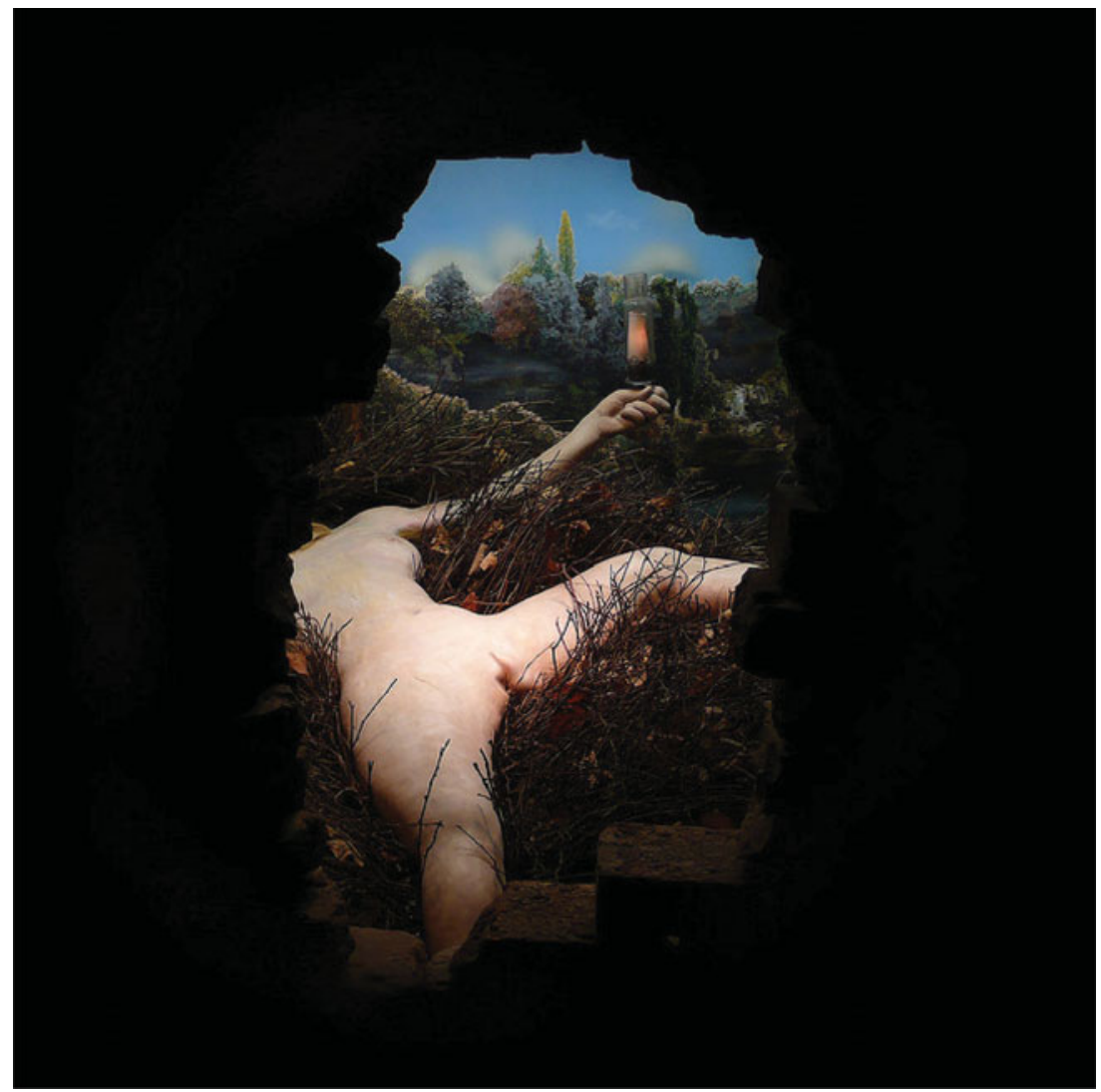

Fig. 4. (Colour online) Marcel Duchamp, Given 1. The Waterfall 2. The Illuminating Gas (1946-66). (C) Succession Marcel Duchamp/ADAGP, Paris/Artists Rights Society (ARS), New York, 2017.

of transcendence from ordinary life and the limitations of material existence, albeit an entirely private and personal one. In this sense, for all the extremity of his assault on the category of art, Duchamp may have in fact remained an artist.

For Seigel, then, Duchamp's legacy is a mixed one. He is a figure who pushed individual autonomy to its limits, reveling in the unbounded freedom of the imagination, while also sundering the bonds of communication between artist and audience. At the same time, recognizing that his refuge was a private and personal one, he resisted the attempts to generalize the freedom he located therein, maintaining the boundary between private and public reality, the freedom of the individual imagination and that which is possible to materialize and institutionalize. If he is Seigel's exemplary antihero of modern culture, then Duchamp is not without his heroism either. 